\title{
Facile synthesis of silver nanoparticle and their potential application
}

\author{
Ananya Shukla, Bharat A. Makwana* \\ Department of Chemistry, H.V.H.P. Institute of Post Graduate studies and Research,Sarva Vidyalaya Campus, Kadi, \\ Kadi Sarva Vishwavidyalaya (KSV University), India
}

Email address:

Dr.b.a.makwana@hotmail.com (B. A. Makwana),bhrtchem1@gmail.com (A. Shukla)

To cite this article:

Ananya Shukla, Bharat A. Makwana. Facile Synthesis of Silver Nanoparticle and Their Potential Application. American Journal of Nanoscience and Nanotechnology. Vol. 2, No. 4, 2014, pp. 84-92. doi: 10.11648/j.nano.20140204.14

\begin{abstract}
Our research focused on the production, characterization and application of silver nanoparticles (AgNPs), which can be utilized in biomedical research and environmental cleaning applications. We used an environmentally friendly Green synthetic technique for the production of the AgNPs. The Vitex negundo leaf extract used to produce the nanoparticles were from aqueous extracts. Synthesis of colloidal AgNPs was monitored by UV-Visible spectroscopy. The UV-Visible spectrum showed a peak between $410 \mathrm{~nm}$ corresponding to the Plasmon absorbance of the AgNPs. The method used for the preparation of silver nanoparticles was found to be rapid and require no toxic chemicals. The Vitex negundo capped silver nanoparticles were characterized by UV/Vis-spectroscopy, Particle size analyzer (PSA), Transmission electron microscopy (TEM) and Energy dispersive X-ray Analysis (EDX). Duly characterized nanoparticles were explored for their application as antimicrobial agent were also found to exhibit reasonably good antimicrobial activity when compared with standard Chloramphenicol, which suggests its potential use as antimicrobial agent with Gram-negative and Gram-positive bacteria, which is not toxic for human healthy cells, but inhibit bacterial growth.
\end{abstract}

Keywords: Silver Nanoparticle, AgNps, Antimicrobial, Green Synthesis

\section{Introduction}

Nanotechnology is an important field of modern research dealing with design, synthesis, and manipulation of particles structure ranging from approximately 1-100 nm. Tremendous growth in this emerging technology has opened novel fundamental and applied frontiers, including the synthesis of nanoscale materials and exploration or utilization of their exotic physicochemical and optoelectronic properties. Nanotechnology is rapidly gaining importance in a number of areas such as health care, cosmetics, food and feed, environmental health, mechanics, optics, biomedical sciences, chemical industries, electronics, space industries, drug-gene delivery, energy science, optoelectronics, catalysis, reorography, single electron transistors, light emitters, nonlinear optical devices, and photoelectrochemical applications[1,2]

Silver nanoparticles are of interest because of the unique properties (e.g., size and shape depending optical, electrical, and magnetic properties) which can be incorporated into antimicrobial applications, biosensor materials, composite fibers, cryogenic superconducting materials, cosmetic products, and electronic components. Several physical and chemical methods have been used for synthesizing and stabilizing silver nanoparticles[3, 4]. The most popular chemical approaches, including chemical reduction using a variety of organic and inorganic reducing agents, electrochemical techniques, physicochemical reduction, and radiolysis are widely used for the synthesis of silver nanoparticles. Recently, nanoparticle synthesis is among the most interesting scientific areas of inquiry, and there is growing attention to produce nanoparticles using environmentally friendly methods (green chemistry). Green synthesis approaches include mixed-valence polyoxometalates, polysaccharides, Tollens, biological, and irradiation method which have advantages over conventional methods involving chemical agents associated with environmental toxicity. This chapter presents an overview of silver nanoparticle preparation by physical, chemical, and green synthesis approaches. The aim of this chapter is, therefore, to reflect on the current state and future prospects, especially the potentials and 
limitations of the above mentioned techniques for industries. Moreover, we discuss the applications of silver nanoparticles and their incorporation into other materials, the mechanistic aspects of the antimicrobial effects of silver nanoparticles.

The field of nanoscience has been established recently as a new interdisciplinary science which can be defined as a whole knowledge on fundamental properties of nano-size objects [5]. Size and shape of nanoparticles provide an efficient control over many of their physical and chemical properties [6, 7], and their potential application in optoelectronics [8,9], recording media [10, 11], sensing devices [12, 13], medicine [14-16] and catalysis [17]. Silver nanoparticles(NPs) have unique electronic and optical properties, and hence they have been used in a broad range of fields, including catalysis, biological labelling and photonics etc. [18-23]. Ag ions and AgNPs were found to be highly toxic to microbes, with strong biocidal effects. Silver nanoparticles possess potential application to eliminate microorganisms and hold the promise of killing microbes effectively [24, 25].

Hence, synthesis and application of Ag nanoparticles are an important area of research. Various methods, including aerosol technique [26], electrochemical or sonochemical deposition [27, 28], photochemical reduction [29], laser irradiation technique, etc. [30], have been reported over the last two decades for the synthesis of silver nanoparticles. Widely used is chemical reduction method, which involved the reduction of metal ions with the help of different reducing agents such as citric acid, borohydride (Lee and Meisel Method) [31], $\mathrm{N}_{2} \mathrm{H}_{4}$ [32], $\mathrm{NH}_{2} \mathrm{OH}$ [33], ethanol [34], ethylene glycol [35] and $N, N$-dimethyformamide (DMF) [36]. Other organic compounds which not only act as reducing agent but also as stabilizing agent to prevent the nanoparticles from aggregation like cetyl trimethylammonium bromide [37], sodiumdodecyl sulphate [38], poly(vinyl alcohol) [39] and poly(vinylpyrrolidone) [40] poly (lactic Acid) [41] poly (methyl vinyl ether) [42] have also been used for the synthesis of nanoparticles but they suffer from aggregation.

In fact, metal nanoparticles can be converted into powerful nanoscale chemical sensors by manupulating their surface with those molecules which can introduce new functionality and also possess additional binding sites to interact with substrates, such as metal ions in solution. Therefore, detection and sensing of heavy and transition metal ions via multifunctional nanoparticles [43] are topics of recent interest in nanoscience.

Characterization of nanoparticles was done by UV/Visspectroscopy, particle size analyzer (PSA), Transmission electron mictroscopy (TEM) and energy dispersive X-ray Analysis (EDX). As the size [21, 44] and zeta potential [30, 45] of fluorescent CPH-AgNPs was found to be suitable for biological applications, therefore, basic antimicrobial activity has also been screened against microorganisms like Escherichia coli, Bacillus megaterium, Staphylococcus aureus and Bacillus subtilis.

\section{Synthesis of Silver Nanoparticles}

\subsection{Materials and Methods}

\subsubsection{Materials}

All the reagents and metal salts of AR grade were purchased from Sigma-Aldrich and used without further purification. Solvents used for spectroscopic studies were purified and dried before use. All aqueous solutions were prepared from quartz distilled deionized water, which was further purified by a Millipore Milli-Q water purification system (Millipack 20, Pack name: Simpak 1, Synergy). Melting points (uncorrected) were taken in a single capillary tube using a VEEGO (Model No: VMP-DS, India) melting point apparatus. The colloidal solutions were centrifuged in REMI, Model No. R-8C laboratory centrifuge.The The spectra were recorded at room temperature. Absorption spectra were studied on a Jasco V$570 \mathrm{UV}-\mathrm{Vis}$ recording spectrophotometer. $\mathrm{pH}$ of the solutions was measured using $\mathrm{pH}$ analyzer LI 614- Elico. The particle size and zeta potential were determined by using the Malvern Zetasizer (Model; ZEN3600) as such without dilution. TEM images were recorded in MACK/model JEOL, JEM 2100 at an accelerated voltage of $200 \mathrm{kV}$. A drop of dilute solution of a sample in water on carbon coated copper grid was dried in vacuum and directly observed in the TEM. The antimicrobial susceptibility of nanoparticles was evaluated using the disc diffusion or Kirby-Bauer method and zones of inhibition were measured after 24 hours of incubation at $35^{\circ} \mathrm{C}$.

\subsubsection{Medicinal use of Vitex Negundo}

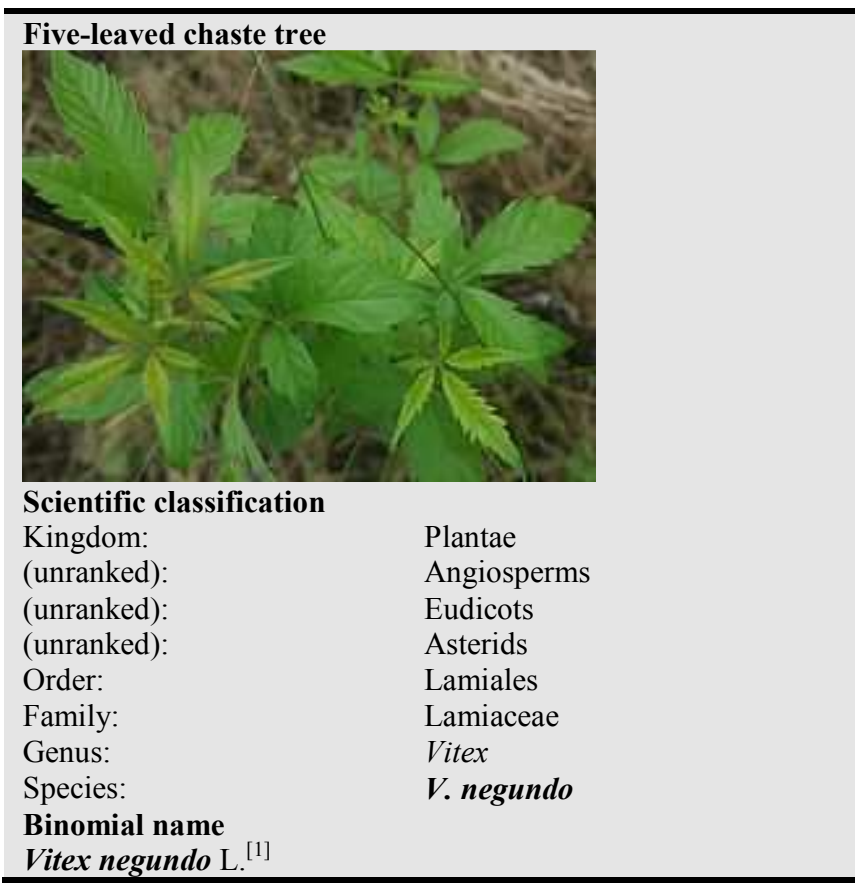

The principal constituents the leaf juice are casticin, isoorientin, chrysophenol D, luteolin, p-hydroxybenzoic acid and D-fructose The main constituents of the oil are 
sabinene, linalool, terpinen-4-ol, $\quad \beta$-caryophyllene, $\alpha$ guaiene and globulolconstituting $61.8 \%$ of the oil. In vitro and animal studies have shown that chemicals isolated from theplanthave potentialanti-inflammatory, antibacterial, antifungal and analgesic activities. Vitex negundo is used for treating stored garlic against pests and as a cough remedy in the Philippines. Roots and leaves used in eczema, ringworm and other skin diseases, liver disorders, spleen enlargement, rheumatic pain, gout, abscess, backache; seeds used as vermicide[46].

\subsection{Medical Uses of Vitex Negundo}

Properties of Vitex negundo as a medicinal plant include antihistamine, antioxidant, and anticonvulsant uses. It also produces pain relief similar to aspirin and morphine in animal tests. This plant has been used for hundred of years in India and in the Philippines, where the health department endorsed its use as an herbal medicine.

Scientific studies examined the leaves, roots, fruits, and flowers of the plant, and found possible medicinal uses in animal studies. The leaves, root, and fruit showed antihistamine benefits that might relax bronchial muscles and reduce asthma symptoms. The studies also found antiinflammatory properties that may treat arthritis and rheumatism. Researchers discovered extracts of this plant did not cause stomach damage in rats even when toxic doses were administered.

Another study tested the anticonvulsant benefits of Vitex negundo in laboratory animals. Rats were dosed with leaf extract before chemicals to induce seizures were administered. These experiments found Vitex negundo provided protection against seizures similar to anticonvulsant drugs approved for human use. The scientists concluded the medicinal uses of the plant for seizures might produce fewer side effects than typical medications.

The leaves produce a cooling effect that eases pain and swelling. The juice of Vitex negundoleaves commonly serves as a treatment for sprained ankles, arthritis pain, and injuries. At high doses in animal studies, pain relief similar to morphine was attained by researchers. At low doses, the plant provides relief equal to aspirin, but without upsetting the stomach.

Fruit from Vitex negundo serves as an aphrodisiac in some regions. It also promotes fertility and might regulate menstrual cycles. The flowers act as an astringent and digestive aid, and are promoted to treat heart disease in some areas.

Filipinos burn leaves of the plant to repel mosquitoes and house flies. Oil from the leaves is also used to deter pests in grain storage facilities. Tests show the oil might also be an effective pesticide on insects that damage tobacco leaves.

More than 200 species of the plant exist, with 14 found in India, where it is considered a common herbal remedy. Vitex negundo is also known as the five-leafed chaste tree or monk's pepper. Its most striking feature centers on a cluster of five pointed leaves resembling a hand. This plant grows as a shrub or small tree from a single trunk.

\subsection{Preparation and Characterization of AgNps}

Vitex Negunda were collect from S.V Campus Kadi, Department of Chemistry garden.. The extraction sample was prepared by extracting the leaf of vitex Negundo and storing it for the synthesis of AgNPs (Scheme 1).

In a typical one pot method, silver nanoparticles were prepared by the adding $25 \mathrm{ml}$ of $1 \mathrm{mM}$ aqueous solution of Vitex Negundo leaf extract to the conical flask containing $25 \mathrm{ml}$ of $1 \mathrm{mM}$ boiling solution of $\mathrm{AgNO}_{3}$. Heating of the resulting solution was continued for another 20 minutes on hot water bath with continuous stirring till the colour of the solution changed to permanent turbid yellow. The turbid yellow solution was centrifuged at $5000 \mathrm{rpm}$ for 5-7 minutes to get rid of supernatant liquid which might contain any unreacted reactants. The residue of nanoparticles was redispersed in water to get back the nanoparticles. This process was repeated three times and the absence of reactants in supernatant liquid was confirmed by UV- Visible spectrophotometry. The particle size, morphology and composition of the nanoparticles were determined by transmission electron microscopy (TEM) and energy dispersive X-ray Analysis (EDX).

\subsection{Antibacterial Activity of CPH-AgNps}

The antibacterial activity of silver nanoparticles was evaluated using the disc diffusion and Kirby-Bauer method [30]. The antibacterial assays were done on bacterial organisms like Escherichia coli, Bacillus megaterium, Staphylococcus aureus, Bacillus subtilis, by Muller Hinton Agar (MHA) plates. Sterile paper disc of $10 \mathrm{~mm}$ diameter containing silver nanoparticles and standard antibiotic chloramphenicol $(100 \mu \mathrm{g} / \mathrm{ml})$ containing discs were placed on each plate as control. The plates were incubated at $35^{\circ} \mathrm{C}$ overnight, and the inhibition zones around the discs were measured.

\section{Preparation of Nanoparticle}

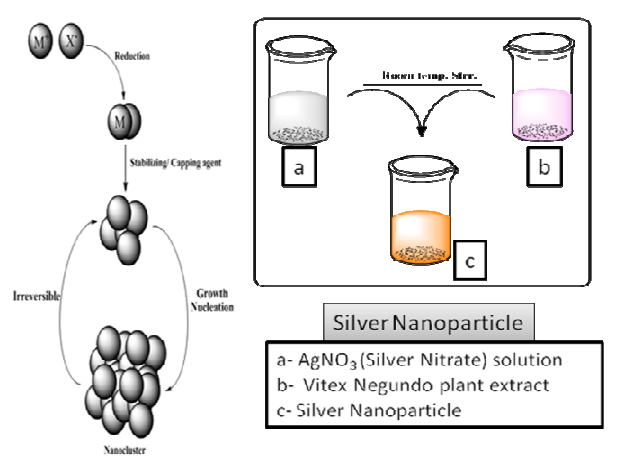

Scheme 1. Preparation of nanoparticles 


\section{Results and Discussion}

\subsection{Formation of Silver Nanoparticles and its Mechanism}

Plants contain a complex network of antioxidant metabo- lites and enzymes that work together to prevent oxidative damage to cellular components. Pineapple contains a number of essential nutrients, including vitamin $\mathrm{C}$, man-ganese, and fibre. It also contains beneficial plant phyto- chemicals (Ferulic acid and chlorogenic acid) which have antioxidant and anti-cancer activities. These antioxida- tive compounds delay or inhibit the oxidation of mole- cules by inhibiting the initiation or propagation of oxida- tive chain reaction. The antioxidative activity of phenolic compounds is mainly due to their redox property, which plays an important role in absorbing and neutralizing free radicals, quenching singlet and triplet oxygen or decom- posing peroxides[47]. Several reports have conclusively shown close relationship between total phenolic contents and antioxidative capacity[48]. The antioxidant ac- tivity is the result of a combination of different com- pounds having synergistic and antagonistic effect[49].

In this study, we have made use of vitex Negundo plant extract, which acted as both reducing and stabilizing agent in an aqueous medium for the formation of silver nanoparticles (AgNps). Reduction of $\mathrm{AgNO}_{3}$ by leaf extract occurs via oxidation of the amino group or some alkaloids or terepenoids of vitex negundo i.e., transfer of electrons from the functional group to the $\mathrm{Ag}^{+}$ions (Eq.1). Vitex Negundo extract can passivate the surface of silver nanoparticles and stabilize Nanoparticle owing to the coordination of nitrogen atoms or some other group with $\mathrm{Ag}$ atoms at the surface of silver nanoparticles. The resulting metallic silver nucleates to form silver nanoparticles and further stabilize it electro statically as follows [32, 50, 51].

$$
\text { Eq.1 } \mathrm{AgNO}_{3}+\mathrm{RNH} \rightarrow \mathrm{Ag}^{0}+\mathrm{RNH}^{+}+\mathrm{NO}_{3}^{-}
$$

The optical absorbance was recorded on UV-Vis spectrophotometer ( Jasco double beam model) in 200 $800 \mathrm{~nm}$ wavelength range. It was observed that upon addition of the extract into the flask containing the aqueous silver nitrate solution, the colour of the medium changed to yellow within $2 \mathrm{~min}$. This indicated the for-mation of silver nanoparticles. The solution containing the signatory colour of AgNPs (Fig.1).

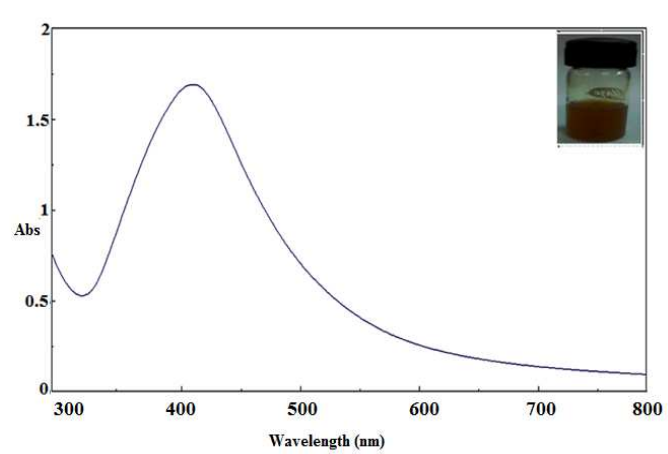

Fig. 1. Absorption spectra of functionalised silver nanoparticles (-AgNps) and inset of figure shows its yellow colour

The size distribution of the AgNps was characterized by two techniques, transmission electron microscopy (TEM) and particles size analyzer (PSA). TEM is used to visualize the shape as well as to measure the diameter of nanoparticles. Whereas, PSA provides information regarding the size of aggregates rather than the diameter of individual particles. (Fig 2a, 2b), depicts that the sample was composed of a large quantity of well dispersed spherical AgNps with an average particle size of $5 \pm 1 \mathrm{~nm}$. From the particle size analyser, the average hydrodynamic diameter of AgNps was found to be $15 \pm 2 \mathrm{~nm}$. These higher values were due to the light scattered by the core particle and the layers formed on the surface of the particles. Energy-dispersive X-ray (EDX) analysis spectrum recorded in the spot-profile mode from one of the densely populated AgNps regions on the surface of film, strong signals from $\mathrm{Ag}$ atoms while weaker signals from $\mathrm{C}$, $\mathrm{O}, \mathrm{Si}, \mathrm{Cu}$ and $\mathrm{Ca}$ atoms were observed (Fig. 2c). Zeta potential, the overall charge of the particle in a particular medium was found to be $+18 \mathrm{mV}$ (Fig 3). The positive charge indicates that the silver nanoparticles were properly capped with positively charged of some component of vitex Negundo leaf extract.

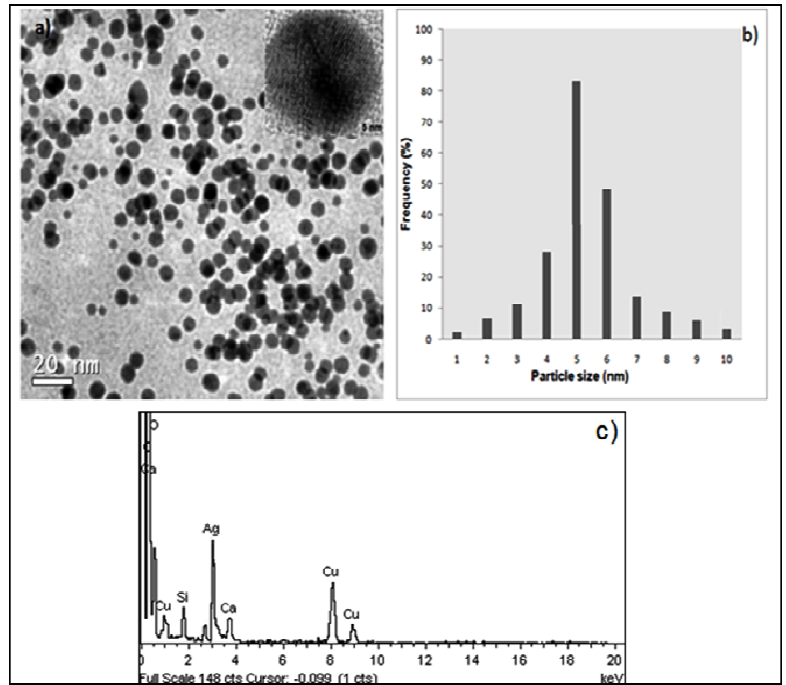

Fig. 2(a). TEM image of Vitex Negundo reduced AgNps. (b) Particle size distribution graph of-AgNps. (c) EDAX spectrum of-AgNps 


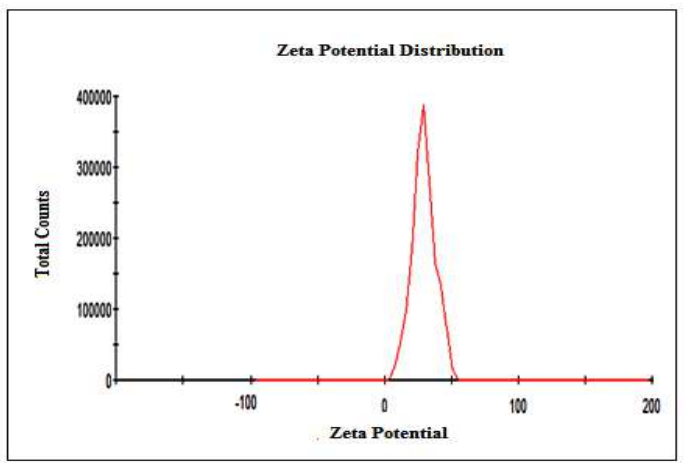

Fig. 3. Zeta potential of Vitex Negundo leaf Extract plant capped-AgNps

\subsection{Antibacterial Activity Study of AgNps}

With regard to antibacterial activity, it is well known that the nanoparticles smaller than $10 \mathrm{~nm}$ interact with bacteria and produce electronic effects [21, 52], which enhanced the reactivity of nanoparticles. Thus, it is corroborated that the bactericidal effect of silver nanoparticles is size dependent $[53,54]$.

Hence, it is worth studying the antibacterial behaviour of synthesised -AgNps of $5 \mathrm{~nm}$ particle size and with $+18 \mathrm{mV}$ zeta potential value (Fig.4). Although the exact mechanism of action of silver on the microbes is still not known but the suggested possible mechanism of action of metallic silver, silver ions and silver nanoparticles is according to their morphological and structural changes found in the bacterial cells. Some studies have reported that the positive charge of silver ions is crucial for its antimicrobial activity through the electrostatic attraction between negative charge cell membrane of microorganisms and positive charge nanoparticles [30, 45]. The nanoparticles get attached to cell membrane and also penetrate inside the bacteria. The bacterial membrane contains sulfur-containing proteins, and the silver nanoparticles interact with these proteins in the cell as well as with the phosphorus containing compounds like DNA. When silver nanoparticles enter the bacterial cell, they form a low molecular weight region in the centre of the bacteria to which the bacteria conglomerate thus, protecting the DNA from the silver ions. The nanoparticles preferably attack the respiratory chain and inhibit cell division finally leading to cell death. The nanoparticles release silver ions in the bacterial cells, which enhance their bactericidal activity (Scheme 2) [55, 56].

The antimicrobial effect of AgNps on bacteria such as Staphylococcus aureus, Escherichia coli, Bacillus megaterium and Bacillus subtilis were compared with standard antibiotics such as chloramphenicol. Zone of inhibition is the only criterion which has been used to compare the antimicrobial activity. On this basis, it was observed that the antimicrobial activity of $\mathrm{AgNps}$ is generally more than the plant extract (Fig.4). Although the antimicrobial activity of $\mathrm{AgNps}$ is slightly less than that of standard chloramphenicol therefore, it is reasonable to propose that AgNps hold the potential of their use as a good antibacterial agent. (Table 1)
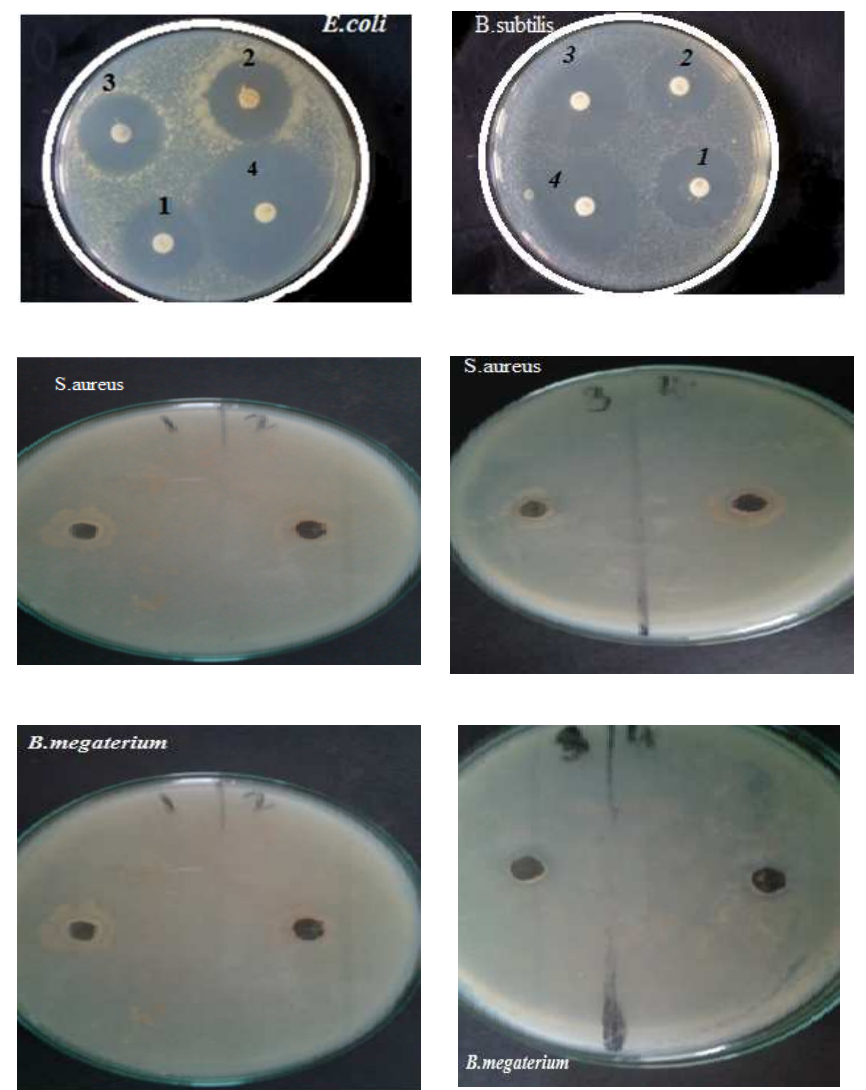

Fig.4. Antimicrobial Activity of SilverNanoparticles with various Micro orginisms

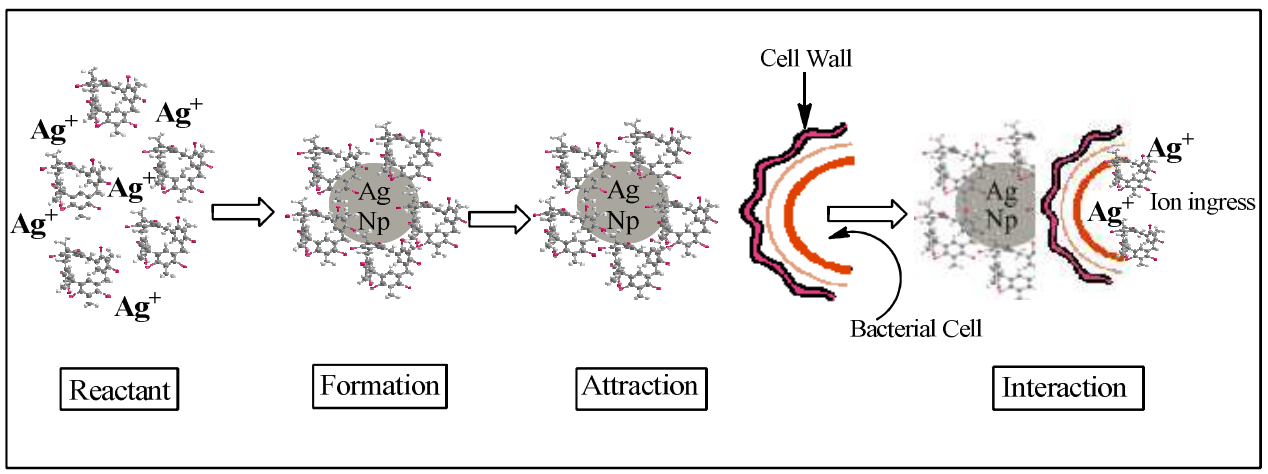

Scheme 2. Praposed antimicrobial Activity of silver Nanoparticle 
Table 1. Antimicrobial activity (Zone of inhibition in $\mathrm{mm}$ ) of Compounds 1-4.

\begin{tabular}{|c|c|c|c|c|c|c|c|c|}
\hline \multirow{3}{*}{ Name of compound } & \multicolumn{8}{|c|}{ Zone of inhibition (mm) } \\
\hline & \multicolumn{2}{|c|}{ E.coli } & \multicolumn{2}{|c|}{ B.subtilis } & \multicolumn{2}{|l|}{ S.aureus } & \multicolumn{2}{|c|}{ B.megaterium } \\
\hline & $50 \mathrm{ppm}$ & 100 ppm & $50 \mathrm{ppm}$ & 100 ppm & $50 \mathrm{ppm}$ & $100 \mathrm{ppm}$ & $50 \mathrm{ppm}$ & $100 \mathrm{ppm}$ \\
\hline $\mathrm{A}^{*}$ & 9 & 8 & 10 & 10 & 9 & 8 & 9 & 7 \\
\hline $\mathrm{AgNO}_{3}$ & 6 & 4 & 7 & 4 & 8 & 8 & 6 & 5 \\
\hline Vitex Negundo leaf & 6 & 5 & 4 & 5 & 5 & 5 & 5 & 5 \\
\hline $\begin{array}{l}\text { AgNps } \\
\text { (Centrifuge) }\end{array}$ & 7 & 6 & 6 & 6 & 5 & 5 & 6 & 5 \\
\hline $\mathrm{AgNps}$ & 7 & 8 & 9 & 8 & 6 & 5 & 8 & 7 \\
\hline
\end{tabular}

$\mathrm{A}^{*}=$ Chloramphinicol (Antibiotic control)

\section{Conclusions}

In conclusion, an efficient, eco-friendly and simple Green synthesis method has been developed for the preparation of AgNps, where vitex Negundo acted as both reducing as well as stabilizing agent. The bio- reduction of aqueous $\mathrm{Ag}+$ ions by the leaf extracts of the plant has been demonstrated. The reduction of the metal ions through leaf extracts leading to the formation of silver nanoparticles of fairly well defined dimensions. But the capability of other plant parts such as fruit and root as a capping and reducing agent is not tested and not well defined. In the present study we found that leaves were good source for the synthesis of silver nanoparticles has many advantages such as, ease with which the process can be scaled up, economic viability and to obtain smaller particle size. This study demonstrated the possibility of use of biologically synthesized silver nanoparticles and their incorporation in materials, providing them sterile properties. The cotton fabrics incorporated with these silver nanoparticles exhibited antibacterial activity against the common pathogens. Prepared nanoparticles can be used as bactericidal and in wound healing, water purification and also in the field of medicine. It was also found that AgNps with $5 \mathrm{~nm}$ size and $+18 \mathrm{mV}$ zeta potential, exhibited reasonably good antimicrobial activity, when compared with standard Chloramphenicol, through the electrostatic attraction between positively charged nanoparticles and negatively charged cell membrane of microorganisms. This suggests their potential use as an antimicrobial agent.

\subsection{Future Application}

Silver Nanoparticle Applications

Silver nanoparticles are being used in numerous technologies and incorporated into a wide array of consumer products that take advantage of their desirable optical, conductive, and antibacterial properties.

Diagnostic Applications: Silver nanoparticles are used in biosensors and numerous assays where the silver nanoparticle materials can be used as biological tags for quantitative detection.

Antibacterial Applications: Silver nanoparticles are incorporated in apparel, footwear, paints, wound dressings, appliances, cosmetics, and plastics for their antibacterial properties.

Optical Applications: Silver nanoparticles are used to efficiently harvest light and for enhanced optical spectroscopies including metal-enhanced fluorescence (MEF) and surface-enhanced Raman scattering (SERS)

AgNPs have been used extensively as anti-bacterial agents in the health industry, food storage, textile coatings and a number of environmental applications. It is important to note that despite of decades of use, the evidence of toxicity of silver is still not clear. Products made with AgNPs have been approved by a range of accredited bodies, including the US FDA, US EPA, SIAA of Japan, Korea's Testing and Research Institute for Chemical Industry and FITI Testing and Research Institute As anti-bacterial agents, AgNPs were applied in a wide range of applications from disinfecting medical devices and home appliances to water treatment Moreover, this encouraged the textile industry to use AgNPs in different textile fabrics. In this direction, silver nanocomposite fibers were prepared containing silver nanoparticles incorporated inside the fabric The cotton fibers containing AgNPs exhibited high anti- bacterial activity against Escherichia coli. Furthermore, the electrochemical properties of AgNPs incorporated them in nanoscale sensors that can offer faster response times and lower detection limits. For instance, electrodeposited AgNPs onto alumina plates gold micropatterned electrode that showed a high sensitivity to hydrogen peroxide.

The optical properties of a metallic nanoparticle depend mainly on its surface plasmon resonance, where the Plasmon refers to the collective oscillation of the free electrons within the metallic nanoparticle. It is well known that the Plasmon resonant peaks and line widths are sensitive to the size and shape of the nanoparticle, the metallic species and the surrounding medium. For instance, nanoclusters composed of 2-8 silver atoms could be the basis for a new type of optical data storage. Moreover, fluorescent emissions from the clusters could potentially also be used in biological labels and electroluminescent Displays (Fig.5) [57]. 

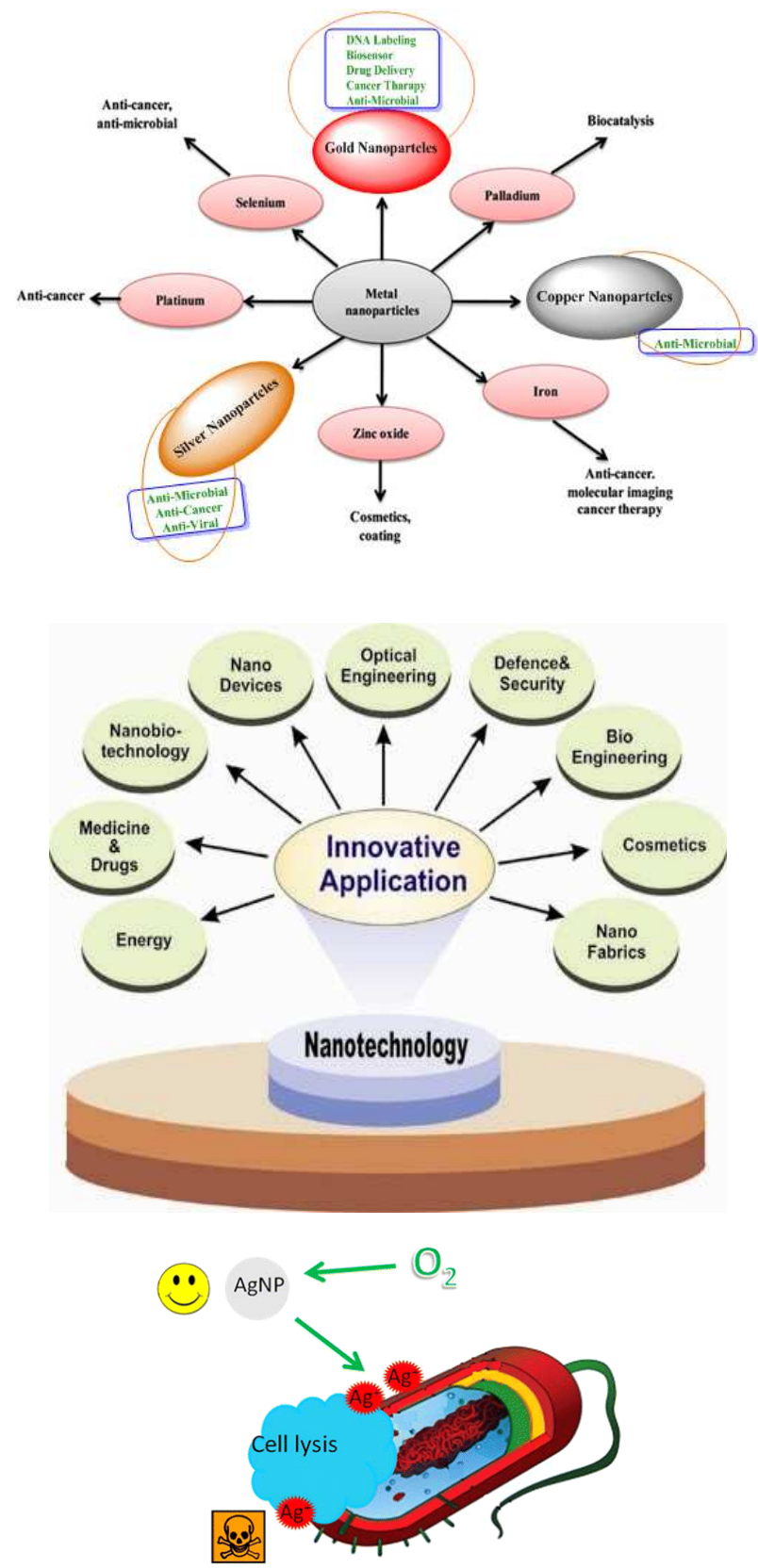

Fig. 5. Application of Silver nano particles

\section{Acknowledgements}

This dissertation work cannot be accomplished without help and views of these noble figures. I convey my deepest regards to all involved in this dissertation.

I am deeply indebted to my guide Dr. B. A. Makwana for his immense concern and encouragement. During these years I have known him as an insightful and principlecentered person. Without his help, this work would not be possible. It is his positive analysis, determination and patience to my idiosyncrasies that has led my research work to this stage.

I am very thankful and wish to express my gratitude to Dr. Deep Joshi, Head of Chemistry Department, for allowing me to undertake the dissertation work. I am also very grateful to Dr. V. K jain, Chemistry Department, School of Sciences for inspirational support and Valuable suggestions.

I express my gratitude to my friends Parth Parikh, Vipul Patel, Jinal patel, Megha patel, for their valuable suggestions and support. I am heartily thankful to all my colleagues specially, who helped me at various stages of this work. I would like to thank, Haribhai patel for helping me in library facility. I am also thankful to Inflibnet, which provided a great source of help for accessing the e-journals. I extend my thanks to the entire non-teaching staff of chemistry department \& the administrative staff of Pramukh Swami Science collage.

I am gratefully acknowledge CSMCRI (Bhavanagar), GFSU (Gandhinagar), Gujarat university (Ahmedabad) for providing instrumental facilities and INFLIBNET, Ahmedabad for e-journals. We are also thankful to Department of Biotechnology (Pramukh swami collage) for help in antimicrobial studies.

Words cannot be deputed for the inspiration, moral support and love of my parents. Finally I would like to bow almighty that supported me through thick and thin.

\section{References}

[1] K. Kokubo, A. Hashim, Water soluble single-nano carbon particles: fullerenol and its derivatives, The delivery of nanoparticles. InTech, (2012) 317-332.

[2] G. Schmid, Large clusters and colloids. Metals in the embryonic state, Chem Rev, 92 (1992) 1709-1727.

[3] A. Ahmad, P. Mukherjee, S. Senapati, D. Mandal, M.I. Khan, R. Kumar, M. Sastry, Extracellular biosynthesis of silver nanoparticles using the fungus $<\mathrm{i}>$ Fusarium oxysporum $</ \mathrm{i}>$, Colloids and Surfaces B: Biointerfaces, 28 (2003) 313-318.

[4] T. Klaus-Joerger, R. Joerger, E. Olsson, C.-G. Granqvist, Bacteria as workers in the living factory: metalaccumulating bacteria and their potential for materials science, TRENDS in Biotechnology, 19 (2001) 15-20.

[5] G.B. Sergeev, Nanochemistry, Elsevier Science, 2006.

[6] A.P. Alivisatos, Perspectives on the physical chemistry of semiconductor nanocrystals, The Journal of Physical Chemistry, 100 (1996) 13226-13239.

[7] G.B. Sergeev, T.I. Shabatina, Cryochemistry of nanometals, Colloids and Surfaces A: Physicochemical and Engineering Aspects, 313 (2008) 18-22.

[8] R. Jin, Y.W. Cao, C.A. Mirkin, K. Kelly, G.C. Schatz, J. Zheng, Photoinduced conversion of silver nanospheres to nanoprisms, Science, 294 (2001) 1901.

[9] L.A. Peyser, A.E. Vinson, A.P. Bartko, R.M. Dickson, Photoactivated fluorescence from individual silver nanoclusters, Science, 291 (2001) 103-106.

[10] S. Sun, C. Murray, D. Weller, L. Folks, A. Moser, Monodisperse $\mathrm{FePt}$ nanoparticles and ferromagnetic $\mathrm{FePt}$ nanocrystal superlattices, Science, 287 (2000) 1989-1992. 
[11] E. Mayes, A. Bewick, D. Gleeson, J. Hoinville, R. Jones, O. Kasyutich, A. Nartowski, B. Warne, J. Wiggins, K. Wong, Biologically derived nanomagnets in self-organized patterned media, Magnetics, IEEE Transactions on, 39 (2003) 624-627.

[12] M. Han, X. Gao, J.Z. Su, S. Nie, Quantum-dot-tagged microbeads for multiplexed optical coding of biomolecules, Nature biotechnology, 19 (2001) 631-635.

[13] J. Wang, Nanoparticle-based electrochemical DNA detection, Analytica chimica acta, 500 (2003) 247-257.

[14] M. Moreno-Mañas, R. Pleixats, Formation of carbon-carbon bonds under catalysis by transition-metal nanoparticles, Accounts of chemical research, 36 (2003) 638-643.

[15] T. Yamada, Y. Iwasaki, H. Tada, H. Iwabuki, M. Chuah, T. VandenDriessche, H. Fukuda, A. Kondo, M. Ueda, M. Seno, Nanoparticles for the delivery of genes and drugs to human hepatocytes, Nature biotechnology, 21 (2003) 885-890.

[16] R.A. Freitas, What is nanomedicine?, Nanomedicine: Nanotechnology, Biology and Medicine, 1 (2005) 2-9.

[17] J.A. Rojas-Chapana, M. Giersig, Multi-walled carbon nanotubes and metallic nanoparticles and their application in biomedicine, Journal of nanoscience and nanotechnology, 6 (2006) 316-321.

[18] M. Moskovits, Surface-enhanced spectroscopy, Reviews of Modern Physics, 57 (1985) 783.

[19] N.R. Jana, T.K. Sau, T. Pal, Growing small silver particle as redox catalyst, The Journal of Physical Chemistry B, 103 (1999) 115-121.

[20] Y. Shiraishi, N. Toshima, Colloidal silver catalysts for oxidation of ethylene, Journal of Molecular Catalysis A: Chemical, 141 (1999) 187-192.

[21] J.R. Morones, J.L. Elechiguerra, A. Camacho, K. Holt, J.B. Kouri, J.T. Ramírez, M.J. Yacaman, The bactericidal effect of silver nanoparticles, Nanotechnology, 16 (2005) 2346.

[22] J.Z. Guo, H. Cui, W. Zhou, W. Wang, Ag nanoparticlecatalyzed chemiluminescent reaction between luminol and hydrogen peroxide, Journal of Photochemistry and Photobiology A: Chemistry, 193 (2008) 89-96.

[23] T. Dadosh, J. Sperling, G. Bryant, R. Breslow, T. Shegai, M. Dyshel, G. Haran, I. Bar-Joseph, Plasmonic control of the shape of the Raman spectrum of a single molecule in a silver nanoparticle dimer, ACS nano, 3 (2009) 1988-1994.

[24] M.M. Priya, B.K. Selvi, J. Paul, Green Synthesis of silver nanoparticles from the leaf extracts of Euphorbia hirta and Nerium indicum, DIGEST JOURNAL OF NANOMATERIALS AND BIOSTRUCTURES, 6 (2011) 869-877.

[25] C. Marambio-Jones, E.M.V. Hoek, A review of the antibacterial effects of silver nanomaterials and potential implications for human health and the environment, Journal of Nanoparticle Research, 12 (2010) 1531-1551.

[26] I. Pastoriza-Santos, L.M. Liz-Marzán, Formation of PVPprotected metal nanoparticles in DMF, Langmuir : the ACS journal of surfaces and colloids, 18 (2002) 2888-2894.

[27] S.A. Harfenist, Z. Wang, M.M. Alvarez, I. Vezmar, R.L. Whetten, Highly oriented molecular Ag nanocrystal arrays,
The Journal of Physical Chemistry, 100 (1996) 1390413910.

[28] R. Stiger, S. Gorer, B. Craft, R. Penner, Investigations of electrochemical silver nanocrystal growth on hydrogenterminated silicon (100), Langmuir : the ACS journal of surfaces and colloids, 15 (1999) 790-798.

[29] V.G. Pol, D. Srivastava, O. Palchik, V. Palchik, M. Slifkin, A. Weiss, A. Gedanken, Sonochemical deposition of silver nanoparticles on silica spheres, Langmuir : the ACS journal of surfaces and colloids, 18 (2002) 3352-3357.

[30] S. Pal, Y.K. Tak, J.M. Song, Does the antibacterial activity of silver nanoparticles depend on the shape of the nanoparticle? A study of the gram-negative bacterium Escherichia coli, Applied and environmental microbiology, 73 (2007) 1712-1720.

[31] P. Lee, D. Meisel, Adsorption and surface-enhanced Raman of dyes on silver and gold sols, The Journal of Physical Chemistry, 86 (1982) 3391-3395.

[32] U. Nickel, A. zu Castell, K. Pöppl, S. Schneider, A silver colloid produced by reduction with hydrazine as support for highly sensitive surface-enhanced Raman spectroscopy, Langmuir : the ACS journal of surfaces and colloids, 16 (2000) 9087-9091.

[33] F.e.L. Ivana Srnova'-Sÿloufova', Antonı'n Gemperle, and Juliana Gemperlova', Core-Shell (Ag)Au Bimetallic Nanoparticles: Analysis ofTransmission Electron Microscopy Images, Langmuir : the ACS journal of surfaces and colloids, 16 ( 2000 ) 9928-9935.

[34] S.S. Angshuman Pal, Surekha Devi, Microwave-assisted synthesis of silver nanoparticles using ethanol as a reducing agent, Materials Chemistry and Physics, 114 (2009) 530-532.

[35] L.S. B. Chefetz, M. Pinchas, T. Ginsburg, S. Elmachliy, E. Tel-Or, and, A. Gedanken, New Approach for the Removal of Metal Ions from Water: Adsorption onto Aquatic Plants and Microwave Reaction for the Fabrication of Nanometals, J. Phys. Chem. B, , Vol. 109 (2005).

[36] R.T. Tom, A.S. Nair, N. Singh, M. Aslam, C. Nagendra, R. Philip, K. Vijayamohanan, T. Pradeep, Freely dispersible Au@TiO2, Au@ZrO2, Ag@ TiO2, and Ag@ ZrO2 coreshell nanoparticles: One-step synthesis, characterization, spectroscopy, and optical limiting properties, Langmuir : the ACS journal of surfaces and colloids, 19 (2003) 3439-3445.

[37] S.-I.S. Gil-Jae Lee, Young-Chai Kim, Seong-Geun Oh, Preparation of silver nanorods through the control of temperature and $\mathrm{pH}$ of reaction medium Materials Chemistry and Physics, 84 (2004) 197-204.

[38] K. Szczepanowicz, J. Stefanska, R.P. Socha, Preparation of silver nanoparticles via chemical reduction and their antimicrobial activity, Physicochem Probl Miner Process, 45 (2010) 85-98.

[39] M. Temgire, S. Joshi, Optical and structural studies of silver nanoparticles, Radiation physics and Chemistry, 71 (2004) 1039-1044.

[40] H.S. Shin, H.J. Yang, S.B. Kim, M.S. Lee, Mechanism of growth of colloidal silver nanoparticles stabilized by polyvinyl pyrrolidone in $<\mathrm{i}>\gamma<\mathrm{i}>$-irradiated silver nitrate solution, Journal of colloid and interface science, 274 (2004) 89-94. 
[41] K. Shameli, M.B. Ahmad, W.M.Z.W. Yunus, N.A. Ibrahim, R.A. Rahman, M. Jokar, M. Darroudi, Silver/poly (lactic acid) nanocomposites: preparation, characterization, and antibacterial activity, International journal of nanomedicine, 5 (2010) 573 .

[42] Z. Shervani, Y. Ikushima, M. Sato, H. Kawanami, Y. Hakuta, T. Yokoyama, T. Nagase, H. Kuneida, K. Aramaki, Morphology and size-controlled synthesis of silver nanoparticles in aqueous surfactant polymer solutions, Colloid \& Polymer Science, 286 (2008) 403-410.

[43] A.S. De Dios, M.E. Díaz-García, Multifunctional nanoparticles: Analytical prospects, Analytica chimica acta, 666 (2010) 1-22.

[44] M. Rai, A. Yadav, A. Gade, Silver nanoparticles as a new generation of antimicrobials, Biotechnology advances, 27 (2009) $76-83$

[45] J.S. Kim, E. Kuk, K.N. Yu, J.H. Kim, S.J. Park, H.J. Lee, S.H. Kim, Y.K. Park, Y.H. Park, C.Y. Hwang, Antimicrobial effects of silver nanoparticles, Nanomedicine: Nanotechnology, Biology and Medicine, 3 (2007) 95-101.

[46] O.P. Tiwari, Y.B. Tripathi, Antioxidant properties of different fractions of $<\mathrm{i}>$ Vitex negundo $</ \mathrm{i}>$ Linn, Food Chemistry, 100 (2007) 1170-1176.

[47] P.K. Rai, H. Lalramnghinglova, Ethnomedicinal Plants of India with Special Reference to an Indo-Burma Hotspot Region: An overview, Ethnobotany Research \& Applications, 9 (2011).

[48] F. Jimoh, M. Sofidiya, A. Afolayan, Antioxidant properties of the methanol extracts from the leaves of Paullinia pinnata, Journal of medicinal food, 10 (2007) 707-711.

[49] N. Ahmad, S. Sharma, Green Synthesis of Silver Nanoparticles Using Extracts of Ananas comosus, Green and Sustainable Chemistry, 2 (2012) 141.
[50] M. Chen, Y.G. Feng, X. Wang, T.C. Li, J.Y. Zhang, D.J. Qian, Silver nanoparticles capped by oleylamine: formation, growth, and self-organization, Langmuir : the ACS journal of surfaces and colloids, 23 (2007) 5296-5304.

[51] J. Newman, G. Blanchard, Formation of gold nanoparticles using amine reducing agents, Langmuir : the ACS journal of surfaces and colloids, 22 (2006) 5882-5887.

[52] M. Rai, A. Yadav, A. Gade, Silver nanoparticles as a new generation of antimicrobials, Biotechnol Adv, 27 (2009) 7683.

[53] G.A. Martínez-Castañón, N. Niño-Martínez, F. MartínezGutierrez, J.R. Martínez-Mendoza, F. Ruiz, Synthesis and antibacterial activity of silver nanoparticles with different sizes, Journal of Nanoparticle Research, 10 (2008) 13431348.

[54] S. Shrivastava, T. Bera, A. Roy, G. Singh, P. Ramachandrarao, D. Dash, Characterization of enhanced antibacterial effects of novel silver nanoparticles, Nanotechnology, 18 (2007) 225103.

[55] Q. Feng, J. Wu, G. Chen, F. Cui, T. Kim, J. Kim, A mechanistic study of the antibacterial effect of silver ions on Escherichia coli and Staphylococcus aureus, Journal of biomedical materials research, 52 (2000) 662-668.

[56] F. Raimondi, G.G. Scherer, R. Kötz, A. Wokaun, Nanoparticles in energy technology: Examples from electrochemistry and catalysis, Angewandte Chemie International Edition, 44 (2005) 2190-2209.

[57] K.M. Abou El-Nour, A. Eftaiha, A. Al-Warthan, R.A. Ammar, Synthesis and applications of silver nanoparticles, Arabian Journal of Chemistry, 3 (2010) 135-140. 